\title{
Hypothyroid phenotype of the Tpst 2 mutant mouse is dependent upon genetic background
}

\author{
Yayoi Hosoda, Nobuya SAsaki, and Takashi Agui \\ Laboratory of Laboratory Animal Science and Medicine, Department of Disease Control, Graduate School of Veterinary Medicine, \\ Hokkaido University, Kita 18, Nishi 9, Kita-ku, Sapporo, Hokkaido 060-0818, Japan
}

(Received 16 March 2010; and accepted 12 April 2010)

\begin{abstract}
DW/J-grt is a congenital hypothyroid mouse model that is characterized by growth retardation, significantly lowered T3 and T4 levels, and severe thyroid hypoplasia related to TSH hyporesponsiveness. Previously, we identified the point mutation of the Tpst2 gene in DW/J-grt mice that causes a decrease in the enzymatic activity, and demonstrated that the Tpst 2 transgene rescues the mutant phenotypes both in vitro and in vivo. The severity of hypothyroidism is highly variable indicating the influence of modifier genes in humans. In this study, to identify the modifier/resistant gene(s) to hypothyroidism, we produced congenic strains carrying this Tpst $2^{\text {grt }}$ mutation on the C57BL/6J and 129/SvJcl (129) genetic backgrounds and analyzed growth rate and thyroid function. Interestingly, the 129 congenic mice exhibited normal growth and thyroid function. The result suggests that 129 strain has the modifier(s) of attenuation of hypothyroidism. Therefore, the identification of the modifier loci of 129 mice will provide important new information about the gene(s) related to congenital hypothyroidism.
\end{abstract}

Congenital hypothyroidism $(\mathrm{CH})$ is one of the most frequent endocrinological disorders. It is caused by insufficient production of thyroid hormone in the thyroid gland, and about $1: 3000-4000$ human newborns worldwide are affected by $\mathrm{CH}$ (18). If untreated, they suffer from irreversible growth delay and mental retardation. $\mathrm{CH}$ is caused by both environmental and genetic factors. Molecular genetic analyses have identified four thyroid dysgenesis susceptibility genes in humans: TSH receptor (TSHR) and the genes for transcription factors TTF1 (thyroid transcription factor), TTF2, and PAX8 (paired box gene 8), that are crucial for the normal development of the thyroid $(7,12,19,23)$. Studies of the sponta-

Address correspondence to: Dr. Nobuya Sasaki

Laboratory of Laboratory Animal Science and Medicine Department of Disease Control, Graduate School of Veterinary Medicine, Hokkaido University, Kita-18, Nishi-9, Kita-ku, Sapporo 060-0818, Japan

Tel/Fax: +81-11-706-5107

E-mail: nobsasa@vetmed.hokudai.ac.jp (Nobuya Sasaki) neous mutation and targeted-disruption of the above genes in mice have provided insight into the molecular mechanisms of organogenesis and thereby formed the basis for molecular genetic studies in human patients affected by thyroid dysgenesis (11, $14,16,20)$. Numerous studies have used a candidate gene approach to identify genes involved in common forms of $\mathrm{CH}(1,6)$. However, most forms of $\mathrm{CH}$ appear sporadically, and only $5 \%$ of patients have been reported to possess $\mathrm{CH}$ attributable to any of the four gene mutations mentioned above. Moreover, the incomplete penetrance and the variable expression observed in familial cases of hypothyroidism demonstrate that $\mathrm{CH}$ is a genetically heterogeneous disease. Thus, there is little information available on the genetic factors in the thyroid disease.

The availability of several murine $\mathrm{CH}$ models offers hope, not only in identifying genes involved in common forms of human $\mathrm{CH}$, but also in understanding how genetic background and environmental factors determine the incidence or severity of hypo- 

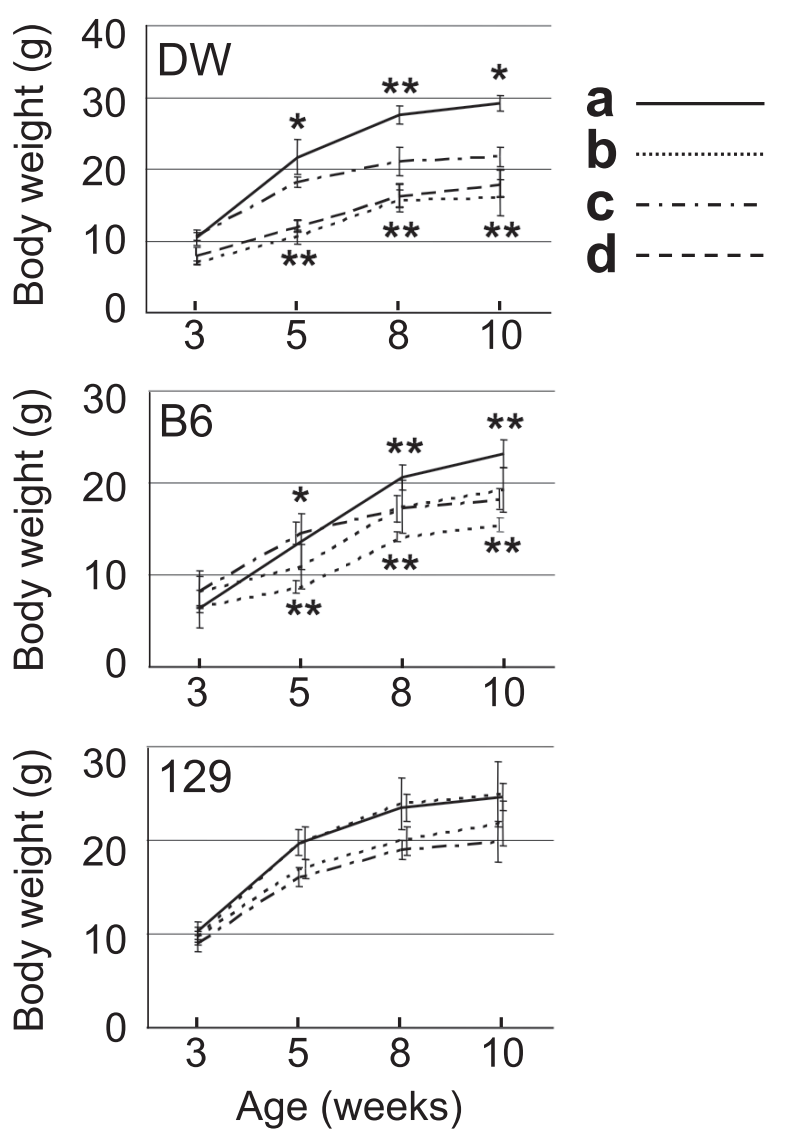

Fig. 1 Growth curve of grt and WT mice of each congenic strain. a: WT male, b: grt male, c: WT female, d: grt female. Student's $t$-test was performed to detect differences in weekly body weight between grt and WT mice. *: $P<0.05$, **: $P<0.01 . \mathrm{n}=4,5,3,4$ for $\mathrm{a}, \mathrm{b}, \mathrm{c}, \mathrm{d}$ in $\mathrm{DW}, \mathrm{n}=5,5,5,4$ for $a, b, c, d$ in $B 6$, and $n=7,7,4,5$ for $a, b, c$, $d$ in 129 , respectively.

thyroidism, which may lead to a more precise understanding of $\mathrm{CH}$ and the development of new treatments for hypothyroidism. DW/J-grt mouse has an autosomal recessive, fetal onset, severe thyroid dysgenesis related to TSH hyporesponsiveness (28). We previously determined that these mutant phenotypes are caused by a deficiency in the enzymatic activity of tyrosylprotein sulfotransferase-2 (Tpst2), and severe thyroid hypogenesis and consequent dwarfism are mainly due to the impairment of the tyrosine sulfation of TSHR by TPST2. Since the sulfation of the tyrosine 385 of TSHR by TPST2 is indispensable for the activation of TSH signaling, the mutant mice develop hypothyroidism and dwarfism due to TSH unresponsiveness $(9,15,25)$. The DW/J-grt (DW-grt) displays growth retardation from 3 weeks of age and their body weight is approximately $60 \%$ of wild-type (WT) littermates. On the

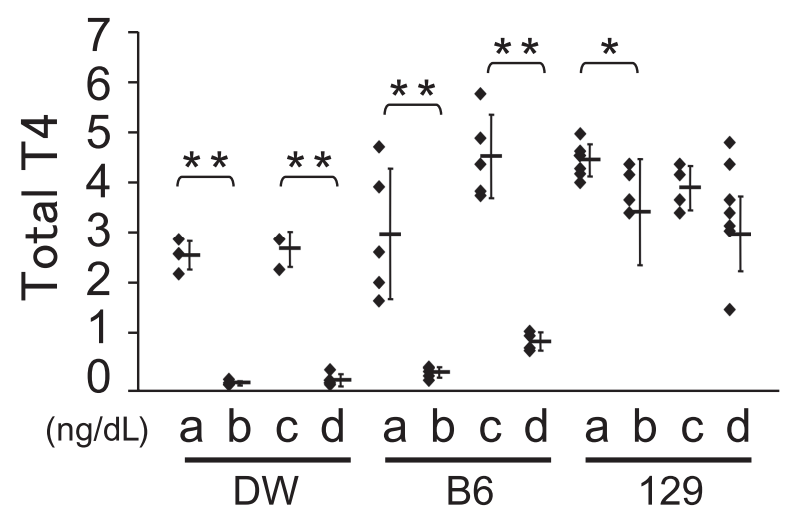

Fig. 2 Plots of serum total T4 at 10 weeks age in the grt and WT mice of each congenic strain. a: WT male, b: grt male, c: WT female, d: grt female. Student's $t$-test was performed to detect differences in total T4 between grt and WT mice. *: $P<0.05,{ }^{* *}: P<0.01 . \mathrm{n}=4,5,3,5$ for $\mathrm{a}, \mathrm{b}, \mathrm{c}$, $d$ in $D W, n=5,5,5,4$ for $a, b, c, d$ in $B 6$, and $n=7,7,4$, 5 for a, b, c, d in 129, respectively.

other hand, Tpst2 knockout (KO) mice derived from the 129 strain show significantly lower serum T3 and T4, and higher serum TSH levels, and thyroid hypoplasia quite similar to that in DW-grt mice (4, 29 ). Despite the symptoms typical of hypothyroidism, Tpst2 $\mathrm{KO}$ mice do not exhibit any apparent growth retardation. In addition, although the heterozygotic KO mice of both thyroid-specific transcriptional factors Ttfl and $\operatorname{Pax} 8$ genes exhibit thyroid abnormality in the C57BL/6J (B6) background, the introduction of the 129 genetic background completely ameliorates the hypothyroid phenotype (1). Thus, we speculated that the 129 strain has higher tolerance to hypothyroidism and subsequent growth retardation.

To verify this hypothesis, we produced congenic strains for Tpst $2^{\text {grt }}$ in B6 (Japan SLC) and 129/SvJcl (129) (Clea Japan) mice. Congenic strains were produced by backcrossing DW-grt to B6 and 129 mice for more than 10 generations (designated B6-grt and 129-grt). Genotyping of the Tpst $2^{g r t}$ allele was performed as described previously (25). The heterozygotic congenic females and males were crossed each other, and Tpst $2^{\text {grt }}$ homozygote, heterozygote and WT mice were born according to the Mendelian rule. The body weight of the B6-grt, 129-grt and their control (B6-WT or 129-WT) littermates was measured at 3, 5, 8 and 10 weeks of age. In the B6grt mice, a significant decrease in body weight was observed from 5 to 10 weeks of age (Fig. 1; $P<$ 0.05 at 5 weeks in males, $P<0.01$ at 8 and 10 weeks in males and 5, 8 , and 10 weeks in females). Interestingly, there were no differences in body 


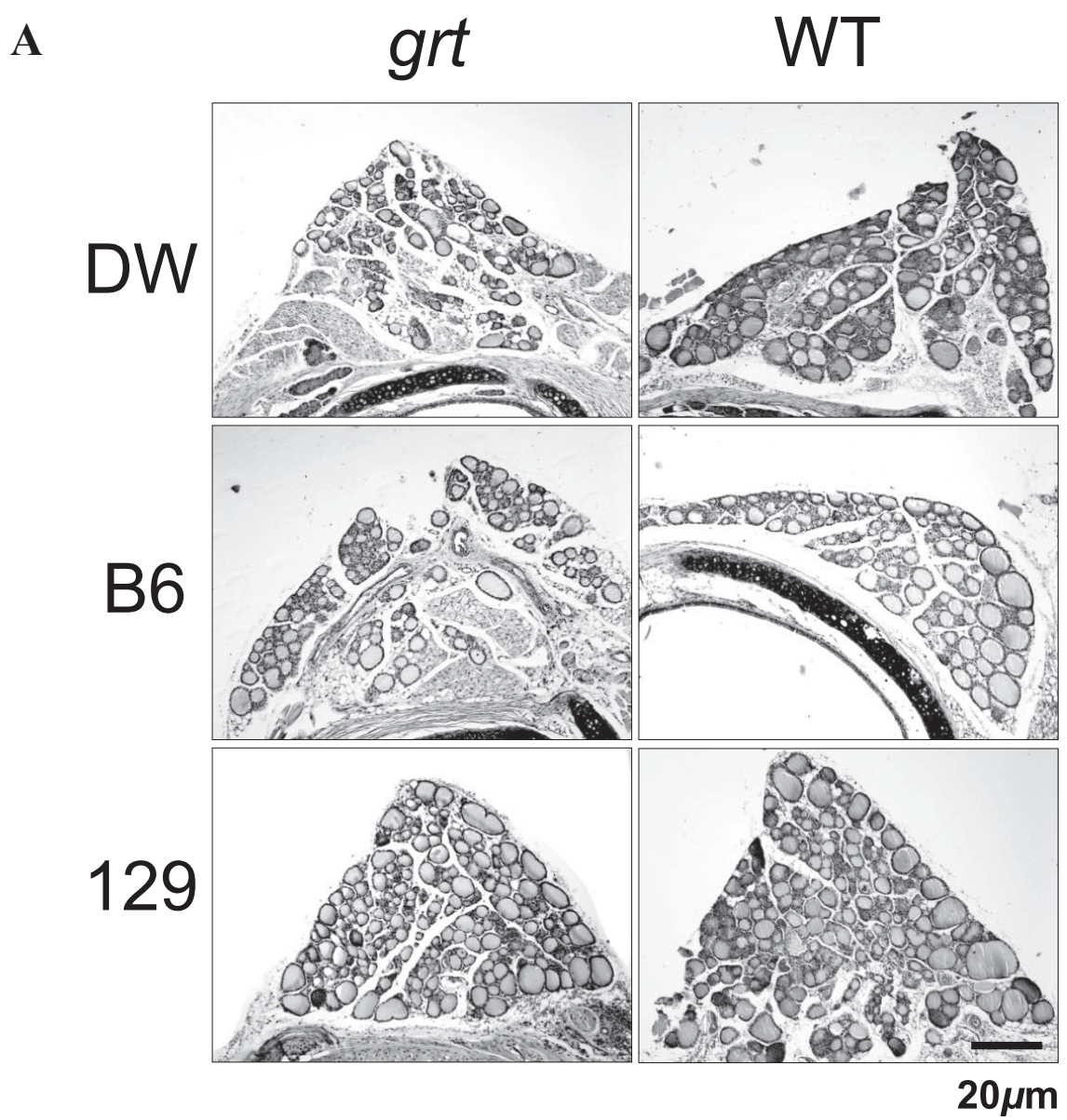

B

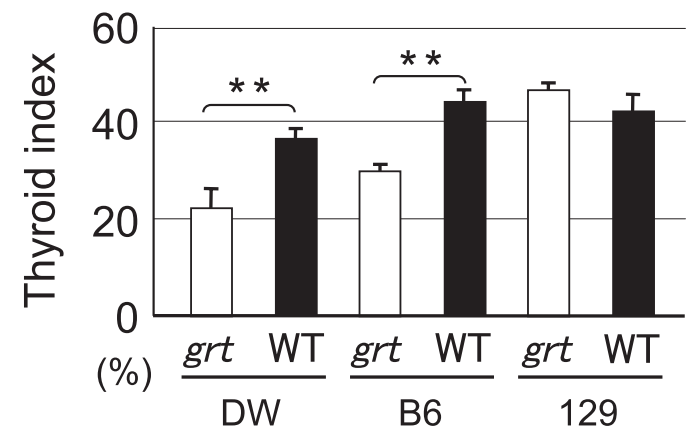

weight between the 129-grt and 129-WT mice (Fig. 1). Next, to validate the correlation between the severity of growth retardation and thyroidal function, we measured serum free T4 levels at 10 weeks using a T4 RIA kit (Siemens Healthcare Diagnostics). In B6-grt mice, the serum level of free T4 was significantly lower than that in B6-WT mice similar to that in DW-grt mice (Fig. 2). On the other hand, the free T4 level in 129-grt mice was similar
Fig. 3 (A) Histological analysis of grt and WT mice of each congenic strain. Thyroid sections of each congenic male mouse at 10 weeks of age are presented. Thyroid glands were fixed with $5 \%$ neutral-buffered formalin and embedded in paraffin. Serial sections of thyroids were cut at $3 \mu \mathrm{m}$ and stained with hematoxylin-eosin.

(B) Thyroid index. Thyroid images at 10 weeks were analyzed by photoshop CS4 (Adobe) and total area of the thyroid cross-section and the sum of the follicle areas were measured by Image J (National Institutes of Health, USA). The average ratio of total follicle areas to total thyroid cross-section area was calculated as the thyroid index. At least 3 distinct sections and more than 3 individuals per group were observed. Student's $t$-test was performed to detect differences between grt (white bars) and WT mice (black bars). ${ }^{\star \star}: P<0.01$.

to that in 129-WT mice. Although a slight decrease in serum free T4 was observed in the 129-grt males, the serum level of free T4 was similar to that in both DW-WT and B6-WT mice. Moreover, to confirm whether a low level of free $\mathrm{T} 4$ is related to thyroid gland morphology, histological analysis was also carried out. The thyroids of the B6-grt mice showed hypoplastic symptoms of a similar severity to those of DW-grt mice in terms of diversity in the 
follicle size (particularly in small follicles), reduction in follicular cell number and replacement of some hypoplastic portions by adipose tissue (Fig. 3A). By contrast, the 129-grt mouse thyroids appeared normal and similar to those in 129-WT mice. For the quantitative evaluation of the severity of thyroid dysplasia, we used a "thyroid index" (average ratio of total colloid areas per thyroid crosssection area). The thyroid indices in DW-grt and B6-grt mice were 30-40\% lower than those of their WT littermates (Fig. 3B). In contrast, the index in 129-grt mice was almost identical to that in 129-WT mice. Taken together, these data indicate that B6 as well as DW mice are susceptible to growth retardation associated with hypothyroidism. In contrast, the thyroid function in 129-grt mice is fully recovered irrespective of TPST2 deficiency, and the 129 strain is remarkably resistant to hypothyroidism.

In this study, the reason for the high resistance to $\mathrm{CH}$ in the 129 strain remains unclear, but there are at least two possibilities: an excess production of factor(s) to stimulate thyrocyte proliferation, or a decrease or defect(s) in the molecules that repress thyrocyte proliferation. In the thyroid, TSH-TSHR signaling is essential for the proliferation and maintenance of the differentiated thyroid follicular cell functions (21). However, the alternative signaling pathways required for thyroid hormone biosynthesis are not so well known. For example, TSH-induced proliferation seems to be dependent on the presence of insulin or IGF-1 $(17,22)$. Further, TSH indirectly stimulates thyrocyte proliferation via the induction of the autocrine growth factors $(3,27)$ or growth factor receptors $(5,8)$. The up- or down-regulation of these factors might contribute to the tolerance to TSH hyporesponsiveness in the 129 strain.

Our results show that there are some differences in phenotype among Tpst2 $\mathrm{KO}$ and 129-grt mice. Although both strains do not show any growth disorders, 129-grt show normal T4 levels and the thyroids are histologically normal in appearance, whereas Tpst2 KO mice show lowered T4 levels and thyroid hypoplasia. The reason for these differences might be due to differences in the type of mutation; the former has decreased TPST2 enzymatic activity whereas the latter has a complete loss. Most gene targeting is carried out in cultured ES cells derived from the 129 strain because of its higher efficiency of germline transmission. However, the genetic and phenotypical differences from several common strains remain an impediment to researchers. For example, corpus callosum dysgenesis, which confounds studies of behavioral and cognitive phenotypes, is commonly observed in 129 mouse strains $(10,13)$. Further, the immune response of 129 strains differs from the well-characterized responses of B6 mice $(2,24,26)$. Our data suggests that strain 129 is one of the most unique strains in terms of thyroid research.

In conclusion, we have shown that 129 strains have a genetically high resistance to hypothyroidism. Susceptibility to thyroid disease has been believed to be associated with a genetic background in humans and other animals. This genetic effect is often complex and difficult to identify since it is further modified by environmental factors. The discovery of novel causative gene(s) might lead to the development of treatment strategies for thyroid cell disorders including thyroid tumors and hyperthyroidism as well as hypothyroidism.

\section{Acknowledgement}

This work was supported by the Ministry of Education, Culture, Sports, Science and Technology, Grant-in-Aid for Scientific Research, KAKENHI (18500323) to N.S. and Japan Society for the promotion of Science, KAKENHI (09J05638) to Y.H. and the Kurata Memorial Hitachi Science and Technology Foundation to N.S.

\section{REFERENCES}

1. Amendola E, De Luca P, Macchia PE, Terracciano D, Rosica A, Chiappetta G, Kimura S, Mansouri A, Affuso A, Arra C, Macchia V, Di Lauro R and De Felice M (2005) A mouse model demonstrates a multigenic origin of congenital hypothyroidism. Endocrinology 146, 5038-5047.

2. Bauler TJ, Hughes ED, Arimura Y, Mustelin T, Saunders TL and King PD (2007) Normal TCR signal transduction in mice that lack catalytically active PTPN3 protein tyrosine phosphatase. J Immunol 178, 3680-3687.

3. Becks GP, Logan A, Phillips ID, Wang JF, Smith C, DeSousa D and Hill DJ (1994) Increase of basic fibroblast growth factor (FGF) and FGF receptor messenger RNA during rat thyroid hyperplasia: temporal changes and cellular distribution. $J$ Endocrinol 142, 325-338.

4. Borghei A, Ouyang YB, Westmuckett AD, Marcello MR, Landel CP, Evans JP and Moore KL (2006) Targeted disruption of tyrosylprotein sulfotransferase-2, an enzyme that catalyzes post-translational protein tyrosine O-sulfation, causes male infertility. $J$ Biol Chem 281, 9423-9431.

5. Burikhanov R, Coulonval K, Pirson I, Lamy F, Dumont JE and Roger PP (1996) Thyrotropin via cyclic AMP induces insulin receptor expression and insulin Co-stimulation of growth and amplifies insulin and insulin-like growth factor signaling pathways in dog thyroid epithelial cells. $J$ Biol Chem 271, 29400-29406.

6. Castanet M, Sura-Trueba S, Chauty A, Carré A, de Roux N, Heath S, Léger J, Lyonnet S, Czernichow P and Polak M (2005) Linkage and mutational analysis of familial thyroid 
dysgenesis demonstrate genetic heterogeneity implicating novel genes. Eur J Hum Genet 13, 232-239.

7. Clifton-Bligh RJ, Wentworth JM, Heinz P, Crisp MS, John R, Lazarus JH, Ludgate M and Chatterjee VK (1998) Mutation of the gene encoding human TTF-2 associated with thyroid agenesis, cleft palate and choanal atresia. Nat Genet 19, 399401.

8. Cocks HC, Ramsden JD, Watkinson JC and Eggo MC (2000) Thyroid stimulating hormone increases angiogenic growth factor expression in rat thyrocytes. Clin Otolaryngol Allied Sci 25, 570-576.

9. Costagliola S, Panneels V, Bonomi M, Koch J, Many MC, Smits G and Vassart G (2002) Tyrosine sulfation is required for agonist recognition by glycoprotein hormone receptors. Embo J 21, 504-513.

10. Crawley JN (1996) Unusual behavioral phenotypes of inbred mouse strains. Trends Neurosci 19, 181-182.

11. De Felice M, Ovitt C, Biffali E, Rodriguez-Mallon A, Arra C, Anastassiadis K, Macchia PE, Mattei MG, Mariano A, Schöler H, Macchia V and Di Lauro R (1998) A mouse model for hereditary thyroid dysgenesis and cleft palate. Nat Genet 19, 395-398.

12. Doyle DA, Gonzalez I, Thomas B and Scavina M (2004) Autosomal dominant transmission of congenital hypothyroidism, neonatal respiratory distress, and ataxia caused by a mutation of NKX2-1. J Pediatr 145, 190-193.

13. Gerlai R (1996) Gene-targeting studies of mammalian behavior: is it the mutation or the background genotype? Trends Neurosci 19, 177-181.

14. Gu WX, Du GG, Kopp P, Rentoumis A, Albanese C, Kohn LD, Madison LD and Jameson JL (1995) The thyrotropin (TSH) receptor transmembrane domain mutation (Pro556-Leu) in the hypothyroid hyt/hyt mouse results in plasma-membrane targeting but defective TSH binding. Endocrinology 136, 3146-3153.

15. Hosoda Y, Sasaki N and Agui T (2008) Female infertility in grt mice is caused by thyroid hormone deficiency, not by insufficient TPST2 activity in the reproductive organs. $J$ Vet Med Sci 70, 1043-1049.

16. Kimura S, Hara Y, Pineau T, FernandezSalguero P, Fox CH, Ward JM and Gonzalez FJ (1996) The T/ebp null mouse: thyroid-specific enhancer-binding protein is essential for the organogenesis of the thyroid, lung, ventral forebrain, and pituitary. Genes Dev 10, 60-69.

17. Kimura T, Van Keymeulen A, Golstein J, Fusco A, Dumont JE and Roger PP (2001) Regulation of thyroid cell proliferation by TSH and other factors: a critical evaluation of in vitro models. Endocr Rev 22, 631-656.
18. Kopp P (2002) Perspective: Genetic defects in the etiology of congenital hypothyroidism. Endocrinology 143, 20192024.

19. Macchia PE, Lapi P, Krude H, Pirro MT, Missero C, Chiovato L, Souabni A, Baserga M, Tassi V, Pinchera A, Fenzi G, Gruters A, Busslinger M and Di Lauro R (1998) PAX8 mutations associated with congenital hypothyroidism caused by thyroid dysgenesis. Nat Genet 19, 83-86.

20. Mansouri A, Chowdhury K and Gruss P (1998) Follicular cells of the thyroid gland require Pax8 gene function. Nat Genet 19, 87-90.

21. Marians RC, Ng L, Blair HC, Unger P, Graves PN and Davies TF (2002) Defining thyrotropin-dependent and -independent steps of thyroid hormone synthesis by using thyrotropin receptor-null mice. Proc Natl Acad Sci USA 99, 15776-15781.

22. Medina DL and Santisteban P (2000) Thyrotropin-dependent proliferation of in vitro rat thyroid cell systems. Eur $J$ Endocrinol 143, 161-178.

23. Refetoff S (2003) Resistance to thyrotropin. J Endocrinol Invest 26, 770-779.

24. Rolink AG, Andersson J and Melchers F (2004) Molecular mechanisms guiding late stages of B-cell development. Immunol Rev 197, 41-50.

25. Sasaki N, Hosoda Y, Nagata A, Ding M, Cheng JM, Miyamoto T, Okano S, Asano A, Miyoshi I and Agui T (2007) A mutation in Tpst2 encoding tyrosylprotein sulfotransferase causes dwarfism associated with hypothyroidism. Mol Endocrinol 21, 1713-1721.

26. Schwarz K, Storni T, Manolova V, Didierlaurent A, Sirard JC, Röthlisberger P and Bachmann MF (2003) Role of Tolllike receptors in costimulating cytotoxic $\mathrm{T}$ cell responses. Eur J Immunol 33, 1465-1470.

27. Takahashi S, Conti M and Van Wyk JJ (1990) Thyrotropin potentiation of insulin-like growth factor-I dependent deoxribonucleic acid synthesis in FRTL-5 cells: mediation by an autocrine amplification factor(s). Endocrinology 126, 736745.

28. Tomita K, Yoshida T, Morita J, Atsumi S and Totsuka T (1995) In-vivo responsiveness of thyroid glands to TSH in normal and novel 'growth-retarded' mice: transient elevation in normal mice and impairment in 'growth-retarded' mice. $J$ Endocrinol 144, 209-214.

29. Westmuckett AD, Hoffhines AJ, Borghei A and Moore KL (2008) Early postnatal pulmonary failure and primary hypothyroidism in mice with combined TPST-1 and TPST-2 deficiency. Gen Comp Endocrinol 156, 145-153. 